\title{
Constraining polar amplification with a global compilation of planktonic foraminiferal $\delta^{18} \mathrm{O}$
}

\author{
DANIEL E GASKELL ${ }^{1}$, MATTHEW HUBER ${ }^{2}$, \\ CHARLOTTE L O'BRIEN ${ }^{3}$, GORDON N INGLIS ${ }^{4}$ AND \\ PINCELLI M. HULL ${ }^{1}$
}

${ }^{1}$ Yale University

${ }^{2}$ Purdue University

${ }^{3}$ University College London

${ }^{4}$ National Oceanography Centre Southampton

Presenting Author: daniel.gaskell@yale.edu

Polar amplification - the phenomenon in which changes to the earth's climate tend to produce a larger change in temperature near the poles than the planetary average - is a primary concern in climate dynamics and in forecasting the effects of climate change. This amplification is observed in the geologic record as a decrease in the temperature difference between high and low latitudes under warmer climate states. However, the magnitude of equilibrium polar amplification predicted by climate models remains up to $\sim 10^{\circ} \mathrm{C}$ lower than those derived from empirical compilations, and many of the existing proxy data remain temporally sparse or difficult to interpret. Here, we present a new global compilation of planktonic foraminifera $\delta^{18} \mathrm{O}$ values and use it to produce resolved estimates of polar and equatorial sea surface temperatures for the last 95 million years, accounting for diagenetic concerns. We find a strong and consistent pattern of polar amplification across all climate states over the past $95 \mathrm{Ma}$, with a polar amplification factor (PAR) of $\sim 1.6$. This equilibrium amplification is greater than that predicted by the current generation of global climate models $(\mathrm{PAR} \approx 1.3$ ), but less extreme than that predicted by some prior proxy-based work (e.g., PAR $\approx 2$ ). Our results provide robust constraints for testing the efficacy of global climate models in predicting out-of-state climate systems of the future. 